\title{
DESAFIOS PARA UMA ABORDAGEM EFETIVAMENTE MULTIMODAL DOS GÊNEROS DISCURSIVOS EM LIVROS DIDÁTICOS DE LÍNGUA PORTUGUESA
}

\section{CHALLENGES FOR AN EFFECTIVELY MULTIMODAL APPROACH TO DISCURSIVE GENRES IN PORTUGUESE LANGUAGE TEXTBOOKS}

\author{
Petersonjosé de Oliveira ${ }^{1}$ \\ Recebido em: 19 de setembro de 2021. \\ Revisão final: 14 de novembro de 2021. \\ Aprovado em: 15 de novembro de 2021.
}

RESUMO: Esse artigo é resultado de uma pesquisa bibliográfica que tentou entender como duas coleções didáticas de Língua Portuguesa, utilizadas em 2018, exploraram o material visual na abordagem dos gêneros multimodais. Nesse trabalho tentamos entender quais foram os gêneros multimodais mais usados nas coleções analisadas, e como os autores relacionaram a semiose do visual com o verbal. Nossas observações nos levaram a uma conclusão preocupante: A multimodalidade dos gêneros é tratada como algo acessório à construção do sentido.

Palavras-chave: livro didático, multimodalidade, ensino, Língua Portuguesa, gêneros textuais.
ABSTRACT: This article is the result of a bibliographical research that tried to understand how two didactic collections of Portuguese Language, used in 2018, explored the visual material in the approach of multimodal genres. In this work, we tried to understand which were the most used multimodal genres in the analyzed collections, and how the authors related visual and verbal semiosis. Our observations lead us to a disturbing conclusion: The multimodality of genres is treated as an accessory to the construction of meaning.

Keywords: teaching book, multimodality, teaching, Portuguese Language, textual genders.

1 Possui graduação em Licenciatura em Língua e Literatura Brasileira pela Universidade Federal de Uberlândia (2000), Brasil, e Mestrado em Linguística pela Universidade Federal de Uberlândia (2005), Brasil. Professor do Instituto de Letras e Linguística da Universidade Federal de Uberlândia (ILEEL/UFU), Brasil. Currículo Lattes: http://lattes.cnpq. br/4424176374837628. E-mail: petersonoliveira@ufu.br 
A aula de Língua Portuguesa, no Brasil, passou por muitas transformações metodológicas desde o início do século XX. Durante um longo período, que vinha desde o século XIX, avançando aproximadamente até meados do século XX, as aulas de Língua Portuguesa eram de leitura, de ditado, de declamações de poemas, da escrita à mão, da oratória, da caligrafia. Estavam orientadas para a leitura e escrita de textos escolares ou literários, na sua maioria, e também pela análise gramatical de cunho normativista e metalinguística, com a memorização de classes e termos da oração, regras do bem falar e escrever. A lição de Língua Portuguesa era quase sempre inspirada nas palavras dos grandes mestres gramáticos que, por sua vez, fundamentavam seus julgamentos e análises no método filológico e em exemplos literários ou filosófico-morais.

Como apontam Soares (2004) e Bunzen (2011), os principais instrumentos do professor eram a cartilha (ou antologia de textos) e um compêndio gramatical. As lições de português compunham-se de leitura oral e silenciosa de textos considerados canônicos (literários ou moralizantes), com a análise sintática servindo de instrumento básico da análise das produções escritas. Nada de pluralismo de registros ou variedades linguísticas. O português era um só: o dos grandes escritores portugueses e brasileiros, e a imitação desses mestres era o único modo de acessar o conhecimento do bem falar e do bem escrever. É só depois da década de 1940 que começam aparecer as "lições", isto é, o texto acompanhado por questões. Antes disso, cabia ao professor selecionar o texto e elaborar questões sobre o mesmo.

Dessa limitação de fontes e métodos, pouco restou. Hoje as aulas de Língua Portuguesa vivem a influência e a afluência de um novo modo de ver o ensino da língua materna. $O$ ensino da nomenclatura gramatical, ainda que presente, divide espaço com reflexões sobre a pluralidade de usos e a legitimidade de falares e manifestações linguísticas até bem pouco tempo ignoradas, como a abordagem sociointeracionista dos gêneros discursivos, e ferramentas pedagógicas que vão muito além do quadro-negro e dos livros escolares.

No entanto, mesmo que tenham aparecido na escola o rádio e a TV, o videocassete, a internet e os celulares, o livro didático ${ }^{2}$ continua sendo o instrumento fundamental para o professor nas aulas de Língua Portuguesa. Ainda que divida espaço com outros meios ou materiais, como Datashow, aparelhos de som, televisões e computadores pessoais, na rede pública brasileira o LD continua sendo o eixo em torno do qual gira a rotina do ensinar e aprender português no ensino fundamental e médio.

Com todas as limitações e com todas as transformações por que passou, desde o projeto gráfico, com mais imagens do que nunca, até a inclusão de gêneros multimodais modernos, como reportagens, notícias, música popular, videoclipes, podcasts, blogs, entre outros, a lição de Língua Portuguesa ainda se fundamenta, basicamente em todas as escolas públicas, no modo como o LD a estrutura.

Não se trata aqui de defender que o LD deva orientar a abordagem do professor de forma hegemônica, ou seja, o principal ou único material usado nas aulas. Estamos cientes da rica bibliografia que tem se constituído em torno de uma pedagogia do português voltada a projetos, muitas vezes intra e transdisciplinares. Há muitas e boas pesquisas, que deram fruto a livros em que

2 De agora em diante, $\mathrm{LD}$. 
pesquisadores propõem projetos e intervenções escolares e rompem com o LD de português como única ferramenta de ensino aprendizagem. Ainda assim, em nossa experiência com professores atuantes nas redes públicas e privadas, vemos o LD (ou na forma de apostilas) sendo amplamente utilizado como o principal material pedagógico e que orienta o curso de português nos ensinos fundamental e médio3.

Desde a adoção do PNLD ${ }^{4}$, pelo governo brasileiro em 1985 (mas até mesmo um pouco antes disso), os professores de Língua Portuguesa podem construir suas aulas em torno do LD. Apesar das suas limitações e da inclusão pelas escolas de outras formas de ensino, como os projetos, os livros didáticos, quando bem escolhidos e bem utilizados, são uma inestimável fonte de ideias, exercícios, práticas e reflexões sobre a língua em uso. Num país em que o acesso a fontes escritas impressas de informação e lazer é escasso, ter acesso a um bom material impresso é, muitas vezes, a única possibilidade de informação sobre o assunto de que disporão nossos aprendizes, mesmo se levarmos em conta o fato de que, pela internet (via computadores pessoais ou celulares), uma parte considerável dos estudantes possa ter acesso a outras formas de informação e lazer escrito.

Nesse artigo pretendemos avaliar como essa preciosa ferramenta de ensino vem trabalhando a linguagem visual ou a imagem na aula de Língua Portuguesa. Isto é, verificar como os autores das duas coleções de livros didáticos que analisamos abordam o aspecto visual dos gêneros multimodais e de que forma a leitura da imagem é utilizada em conjunto com a expressão verbal, para a aquisição e o aperfeiçoamento de práticas de linguagem modernas. Interessa-nos, principalmente, compreender se o trabalho nesses livros com a imagem existe, é sistemático e se contribui decisivamente para a expressão verbal, para a compreensão do gênero estudado e para sua produção. Também buscaremos entender quais são os fundamentos teóricos - implícitos e explícitos -envolvidos nessa abordagem.

Sabemos que os livros didáticos de Língua Portuguesa ${ }^{5}$ vêm incorporando uma miríade de

3 Para um breve olhar sobre novas propostas de ensino de gêneros discursivos na aula de Língua Portuguesa, que trazem projetos e intervenções, ver: BUNZEN; MENDONÇA (2013), ROJO; MOURA (2012), DIONISIO; MACHADO; BEZERRA (2010).

4 Em que pesem os critérios exigidos aos autores de LDs por esse programa, nosso trabalho parte da seguinte pressuposto: se os livros não cumprissem de alguma maneira os critérios do PNLD, não teriam sido escolhidos como coleção para o ensino público. Interessa-nos, acima de tudo, saber como os livros tratam os gêneros multimodais em seus exercícios ou lições, já que os elementos mínimos (abordagem do visual ou outras linguagens além da verbal) com o trabalho multimodal aparecem nos LDs analisados. Sabemos que o Programa Nacional do Livro Didático e do material didático, ou PNLD, nas palavras do site oficial do governo, "compreende um conjunto de ações voltadas para a distribuição de obras didáticas, pedagógicas e literárias, entre outros materiais de apoio à prática educativa, destinados aos alunos e professores das escolas públicas de educação básica do País. O PNLD também contempla as instituições comunitárias, confessionais ou filantrópicas sem fins lucrativos e conveniadas com o Poder Público. As escolas participantes do PNLD recebem materiais de forma sistemática, regular e gratuita." (Disponível em: https://www.fnde.gov.br/programas/programasdo-livro. Acesso em: 25 jan. 2012). Constituído desde 1985, o PNLD apresenta uma democratização ao acesso de um material didático de qualidade de modo amplo e gratuito, mesmo que isso implique também o império de oligopólios editoriais e de capital estrangeiros (mais atualmente) na elaboração de materiais e livros com maior apelo comercial. Ver a dissertação de Katia Paulilo Mantovani, O Programa Nacional do Livro Didático - PNLD: impactos na qualidade do ensino público, de 2009 e a tese de Célia Cristina de Figueiredo Cassiano, O mercado do livro didático no Brasil: da criação do Programa Nacional do Livro Didático (PNLD) à entrada do capital internacional espanhol (1985-2007), defendida em 2007.

5 De agora em diante, LDLP. 
gêneros multimodais, além daqueles que já apareciam em LDLP desde as décadas de 1960/1970, como o publicitário e jornalístico, notícias, etc. Praticamente qualquer LDLP hoje fará referência à mídia digital, que é multimodal, por excelência, e se empenhará no letramento digital dos estudantes.

No entanto, os LDLPs incorporaram metodologicamente esses novos gêneros ou continuaram a tratar os elementos visuais destes da mesma forma como o faziam há 50 anos? Será que, ao lado de um olhar mais democrático para novas formas artísticas ou informativas de comunicação e uso da língua portuguesa, a atenção ao letramento visual (como parte dos gêneros multimodais) sofreu alterações, modernizou-se ou aprofundou-se?

Essas questões fundamentaram um projeto de pesquisa desenvolvido no âmbito da instituição onde atuo. Meu interesse e encanto por essa ferramenta pedagógico-metodológica, o livro didático, me fez questionar se as aulas de Língua Portuguesa têm se beneficiado dessa grande abertura para outros gêneros textuais discursivos.

Ao trabalhar com estagiários de Língua Portuguesa, pude perceber o quanto nossos futuros professores demandavam uma formação no aspecto propriamente visual dos gêneros multimodais que apareciam nos livros didáticos ou nas aulas de Língua Portuguesa. Observei uma carência de conhecimento teórico-prático sobre essas questões, e os livros didáticos, onipresentes nas aulas analisadas por meus estagiários e usados em suas aulas simuladas, não eram satisfatórios. Desse modo, no intuito de trazer uma compreensão melhor sobre o visual e o multimodal, propus um projeto para analisar os livros didáticos usados na cidade onde moro.

\section{Corpora da pesquisa e critérios de análise}

Durante o ano de 2018 visitamos de 25 escolas públicas, geridas pelo município ou pelo governo estadual. $\mathrm{O}$ objetivo das visitas era simplesmente saber quais livros didáticos de Língua Portuguesa estavam sendo usados no Ensino Fundamental II e no Ensino Médio, para daí selecionar para análise as coleções ou autores mais usados e, posteriormente, escolher quais coleções abordar primeiro. Como a cidade escolhida como amostra tem cerca de 70 instituições públicas de ensino fundamental, pensamos que a amostragem fosse suficientemente expressiva para entendermos quais LDLP eram os mais utilizados. Além disso, nossa pesquisa não tem a pretensão de ser exaustiva do ponto de visto numérico. Nosso interesse em visitar várias escolas era uma tentativa de não escolher para análise coleções pouco conhecidas pelos professores da cidade.

Apesar de que tais coleções possam ter sido substituídas por outras ou por versões mais novas das mesmas desde que iniciamos esse trabalho ${ }^{6}$, acreditamos que nossa análise poderá iluminar pontos interessantes sobre o letramento multimodal, em especial nos aspectos propriamente visuais dos gêneros multimodais. Além do mais, em estudos posteriores iremos comparar essas coleções com as novas dos mesmos autores, quando forem se adaptando à Base Nacional Comum Curricular

6 Iniciamos o levantamento dos LDLP mais usados em 2018. Logo, várias coleções usadas, ainda eram de edições anteriores a essa data. Havia uma consulta em andamento para escolha dos livros do ensino fundamental II para o ano de 2020 . 
(BNCC). Assim, nossa análise tenta entender como a imagem é abordada nos gêneros multimodais nesse momento e nessas coleções.

As coleções mais usadas pelos professores nas escolas da cidade à época (2018) foram diferentes coleções de William R. Cereja e Thereza C. Magalhães, para o Ensino Fundamental II e o Ensino Médio7. É preciso ainda esclarecer que uma escola que possuísse ambos os níveis de ensino (Ensino Fundamental II e Médio) poderia usar duas coleções diferentes. Desse modo, decidimos analisar, desses mesmos autores, os volumes 1 e 3 da coleção Português: linguagens do Ensino Médio e dois volumes, 6 e 9, da coleção Se liga na língua, de Wilton Ormundo e Cristiane Siniscalchi, do Ensino Fundamental, para comparar as abordagens dos recursos visuais na exploração de gêneros multimodais.

Como o objetivo não é, nesse momento, proceder a uma análise exaustiva de todas as coleções e autores usados, mas obter um instantâneo de como os autores de livros didáticos mais conhecidos e usados tratam a questão da imagem, escolhemos nos deter em duas coleções, de editoras muito tradicionais e conhecidas que, em geral, são as mais requisitadas. Por isso decidimos fazer uma análise comparativa de uma coleção de William Cereja e Thereza Magalhães para o Ensino Médio e uma coleção de Wilton Ormundo e Cristiane Siniscalchi para o Fundamental. Desse modo, apesar de partirmos de uma amostragem ampla, nossa pesquisa tem caráter fundamentalmente qualitativo, não pretendendo um olhar exaustivo de todas as coleções escolhidas pelos professores nesse momento.

Analisar o aspecto visual dos livros didáticos envolve uma gama muita variada de elementos: pode-se partir de aspectos mais técnicos - como tamanho do livro, da cor base do papel e de sua gramatura, se ele é encerado ou não -, já que interferem na intensidade e acuidade do material impresso, sejam letras ou imagens. É possível falar da variedade de tipos, cores, tamanhos das imagens e da palavra impressa utilizadas, do espaçamento ou mancha textual, da quantidade de ilustrações, seus tipos, o lugar em que aparecem. Podemos, também, abordar dos gêneros textuais multimodais: quantos e quais tipos de gêneros multimodais aparecem; quais são objeto específico e detalhado de leitura, análise e produção, ou quais apenas ilustram um tópico gramatical ou assunto. Dentro da análise do material especificamente visual dos gêneros multimodais, pode-se eleger elementos para analisar, como a dimensão da(s) imagem(ns), o formato, a cor, o peso visual dos elementos visuais e dos verbais, o modo como se relacionam. $\mathrm{E}$, ao final, escolhidos os elementos visuais que interessam ao analista (já que é praticamente impossível analisar um "visual" sob todos os pontos de vista possíveis), pode-se procurar entender como os autores dos livros didáticos os abordam, como verbalizam tais elementos, como os relacionam a tópicos como gêneros textuais, aspectos enunciativos e discursivos, análise linguística e semiótica.

Enfim, a análise da visualidade de qualquer LDLP abarca uma série muito ampla de critérios que certamente extrapolam os aspectos mais propriamente "linguísticos". A leitura de imagens e sua relação com os gêneros multimodais é objeto de múltiplas abordagens e áreas, além de envolver

7 Como utilizaremos volumes diferentes dos mesmos autores e anos, vamos usar um sistema de referência com o nome do Livro didático e autores, por nos parecer mais um modo mais claro de leitura. As referências completas estarão no final do artigo. 
debates históricos, sociológicos, filosóficos, artísticos, técnicos ${ }^{8}$. Impossível para um estudioso aprofundar-se em todos eles. No nosso caso, partiremos de um pressuposto mais simples. Tendo em vista o espaço de que dispomos nesse artigo, vamos abordar os seguintes elementos dos gêneros visuais encontrados nos LDs analisados: que tipos de gêneros visuais (ilustrações) ou multimodais são os mais frequentes; se elementos especificamente da semiose visual dos gêneros multimodais são trabalhados de forma sistemática e explícita ou não, e de que forma integram-se a um projeto de construção de um letramento visual integrado ao verbal.

Evidentemente faremos referência de modo mais superficial a outros elementos da visualidade do livro como, por exemplo, a proporção de um gênero em relação a outros, a proporção de elementos não semióticos com os semióticos (especificamente verbais) trabalhados pelos autores. Também aparecerá de forma pontual a relação desses elementos às sugestões de abordagem encontradas na BNCC, que podem ter orientado uma das coleções, Se liga na língua, mas não a outra - Português: linguagens, de publicação anterior à BNCC.

A escolha das coleções de LDLP partiu basicamente do fato de serem livros/coleções muito populares na cidade naquele momento de coleta de dados. A pesquisa não revelou uma hegemonia absoluta dessas coleções, apenas que, em pelo menos 6 escolas das 25 visitadas, essas coleções apareciam como a escolha dos professores de Português. Nenhuma coleção ou autores obteve uma escolha mais expressiva. Também é interessante observar que existem várias coleções diferentes assinadas por William Roberto Cereja e Thereza Cochar Magalhães, usadas nas escolas visitadas, 0 que os constitui como os autores mais populares há anos. Ainda assim, há pelo menos seis coleções de autores diferentes em uso na cidade. Acreditamos que, ao usar como amostra dois volumes da coleção Português: linguagens e dois da coleção Se língua na língua, conseguiremos capturar um panorama razoável, sem a pretensão de sermos exaustivos, do tipo de material visual muito popular nas escolas da cidade. É nossa intenção, ao dar continuidade a essa pesquisa, analisar parte das coleções disponibilizadas para escolha no ano de 2020 pelo PNLD. Assim, teríamos já coleções em tese alinhadas com a BNCC, inclusive a do Ensino Médio que acabou de ser instituída.

Por fim, gostaríamos de ressaltar que alimentamos um profundo respeito pelo trabalho dos autores estudados e estamos conscientes dos desafios que o suporte Livro Didático (para alguns autores, trata-se de um gênero discursivo) oferece a quem precisa encontrar um espaço para falar de tantos gêneros e tantas habilidades e objetos de conhecimento. Entram aí dificuldades adicionais com o formato do suporte, o tamanho, a questão dos direitos autorais de imagens que podem encarecer sobremaneira o material

Em cada volume de cada coleção escolhida, buscamos, inicialmente, obter um apanhado panorâmico e enumerar quais e quantos visuais ${ }^{9}$ cada volume trazia de cada uma das seguintes

8 Os estudos da imagem em geral podem ser objeto da história da arte, sociologia da imagem, análise de discurso, estudos visuais, da semiótica, da semiologia, semântica estrutural greimasiana, da antropologia, da comunicação visual. Isso sem falar aspectos específicos de cada gênero, como pintura, escultura, design visual gráfico, histórias em quadrinhos, publicidade, ilustração, etc.

9 Chamaremos visuais os elementos visuais presentes nos LDLP, a partir da noção presente em Kress e Leeuwen (2006). Para nós, visuais seriam quaisquer elementos que não sejam puramente verbais, isto é, nos quais a presença de elementos como cor, forma, perspectiva, plano, tom, posição, sejam fundamentais para sua leitura. Seria o campo da imagem lato sensu. Nesse campo entram ilustrações, fotos, publicidade, gráficos, entre outros. Evidentemente, alguns visuais são 
categorias: ilustração, fotos puramente ilustrativas, anúncios publicitários, cartazes (reproduções de) pinturas, esculturas, grafites, charges, tiras e gráficos. Depois, procuramos compreender quantos e como são abordados os gêneros mais usados para o ensino de tópicos de Língua Portuguesa: se são utilizados elementos de análise linguística, semiótica ou de elementos de gênero, ou se contam com atividades de compreensão temática ou puramente interpretativa.

Inicialmente, fizemos um levantamento numérico de quantos e quais "gêneros" visuais ou multimodais aparecem nos livros analisados. Diante de tais dados, tentamos refletir sobre os tipos de visuais e a proporção. Num segundo momento, elegemos três visuais mais usados nos livros e procedemos a uma análise preliminar: quantos de cada um deles são abordados explicitamente em seus aspectos visuais. Em uma análise preliminar, percebemos que, nas duas coleções analisadas (Português: linguagens e Se liga na língua) os mesmo três visuais se destacam: ilustrações, quadrinhos/charges e anúncios publicitários. Assim, nossas reflexões enfatizarão tais elementos, mesmo que possamos nos referir a outros visuais presentes nas coleções.

Preferimos abordar apenas os visuais contidos nas unidades-capítulos, e desconsideramos materiais como apêndices, resumos, capas, sumários e índices, por entender que as aulas e planejamentos se concentram no trabalho dos capítulos.

\|lustraçaco: elemento visual predominante e subalternizado do LDLP

Os dois livros da coleção Se liga na língua (volumes 6 e 9) mostraram praticamente o mesmo perfil percentual na divisão dos visuais: o principal visual utilizado é a ilustração, correspondendo a $60 \%$ (vol. 6) e $75 \%$ (vol. 9) dos visuais; as tirinhas ou charges representando $25 \%$ (vol. 6) e 17\% (vol. 9); anúncios publicitários, 10\% (vol. 6) e 4\% (vol. 9). Esses dois últimos visuais estão, na maioria das vezes, associados ao ensino do gênero, à análise linguística e à interpretação geral. Os demais visuais restantes correspondem a $6 \%$ (vol. 6) e $3 \%$ (vol. 9) e são compostos por cartazes, gráficos, poemas ilustrados, fotos (usados como elemento para interpretação, não como pura ilustração), reproduções fotográficas de pinturas e esculturas, xilogravuras, infográficos, storyboards ${ }^{10}$, e aparecem, na maioria absoluta das ocasiões, como exemplo para a teoria gramatical em foco.

Como ponto positivo, observamos que as ilustrações artísticas strictu sensu (desenhadas especialmente para os volumes, uma vez que há fotos e outras imagens prontas que foram utilizadas como ilustração) aparecem muito mais e oferecem uma identidade visual à coleção; além disso, esse tipo de ilustração possibilita a apreciação estética junto do (juntamente com o) texto que as acompanha. Cada um dos volumes, por exemplo, conta com um artista específico: Galvão

gêneros textuais discursivos em si mesmos - tirinhas, charges, cartuns, anúncios publicitários, cartazes, fotografias, etc. No entanto, outros como a ilustração, a fotografia ilustrativa, etc. estão em relação de dependência mais estreita com o texto verbal, não aparecendo isoladas. Desse modo, o conceito de visual é mais abrangente do que o de gênero e, para fins de nossa análise, mais produtivo. Não deixaremos, entretanto, de usar o termo gênero textual-discursivo em casos em que ele se aplica, como ao abordarmos as tirinhas e os cartuns e os anúncios publicitários.

10 Storyboards são roteiros visuais feitos para orientar a execução de um filme. Servem como ponto de apoio para escolher as tomadas de câmeras, os cortes, etc. 
Bertazzi para o volume 9 e Lassmar para o volume 6; tal cuidado, em contratar artistas plásticos especialmente para a coleção, revela um investimento na sua qualidade artístico-visual. No entanto, ainda permaneceu intacta toda uma gama de possibilidades de reflexão oral e escrita sobre o visual ilustrativo. Como visualizamos também na outra coleção analisada (Português: linguagens), a ilustração ocupa/compreende pelo menos $75 \%$ de todo o material visual (imagético) ${ }^{11}$ do LD e por isso pensamos que é um tanto subaproveitada.

Na coleção Se liga na língua, a ilustração ocupa, na maior parte dos casos, um aspecto marginal se levarmos em conta a posição que ocupa na página: a grande maioria das ilustrações vem na extrema direita ou esquerda da página, deixando ao texto a centralidade. Abaixo temos um leiaute típico dessa forma de uso da ilustração.

Figura 1 - Uso da ilustração na coleção Se liga na língua

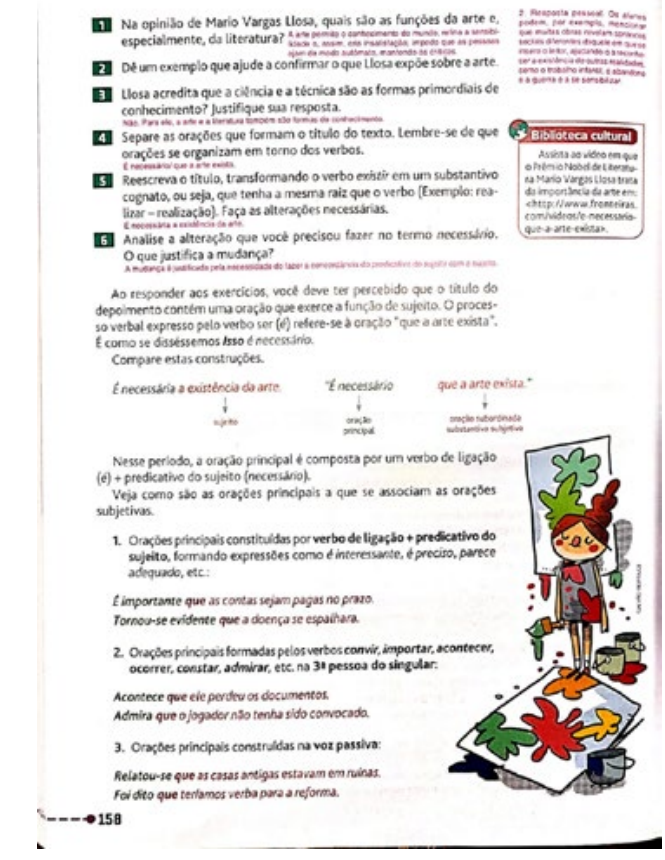

Fonte: ORMUNDO; SINISCALCHI, 2017, p. 158.

Nessa imagem, a ilustração não tem uma relação óbvia com o texto verbal, mas é sugestiva e pede uma leitura mais atenta que a ilumine. Temos a seguinte frase: "É necessária a existência da arte", colocada como exemplo de um tipo de predicado. A ilustração, por sua vez, mostra um desenho de contornos claros, linhas espessas, aproximando a imagem da linguagem dos quadrinhos, com cores chapadas e pouca sugestão de volume. A garota representada mostra seu trabalho artístico com uma atitude de orgulho, mesmo que vejamos manchas por todo o lado, nas telas e no chão. A arte vale a 'bagunça' feita. É uma boa ilustração, porque evita a redundância, acrescenta ao verbal algo não presente no exemplo de predicado. Embora sempre possamos questionar se esse posicionamento à margem estimule o olhar mais atento à ilustração.

Talvez isso se deva simplesmente à tomada de decisão de autores/editores sobre o que é mais importante num LDLP, a imagem ou a palavra. Ou simplesmente por acreditarem que a ilustração é feita como um mero complemento do texto verbal, na maior parte das vezes, dispensável para a compreensão do mesmo. Se nossa interpretação for correta, tal postura denotaria um ponto de 
vista conservador sobre o ensino de Português, tendo em vista o número de gêneros multimodais presentes na BNCC ${ }^{12}$ de 2017 que podem ser objeto de ensino-aprendizagem. Ainda assim, sabemos que num LDLP as explicações teóricas são imprescindíveis, e os textos verbais de diversos gêneros, igualmente. Embora acreditemos ainda na necessidade de os autores e editoras repensarem o papel da ilustração nessa coleção.

Na coleção Português: linguagens, a ilustração permanece como o visual mais utilizado em termos numéricos: $75 \%$ no volume 1 e $85 \%$ no volume 3 . Os outros visuais mais frequentes, anúncios publicitários e tirinhas ou charges, são em geral colocados (usados) para compor lições de análise linguística e ou de gênero, como na coleção Se liga na língua ${ }^{13}$. No volume 1 , a ilustração artística ainda aparece, mesmo que em menor número do que outras fontes de ilustração, como fotos de pinturas, capas de livros e pessoas. Como aspecto fundamental da ilustração dessa coleção, chama a atenção que ela tenha um papel ainda mais subalterno em relação ao verbal do que na coleção Se língua na língua. A maioria das imagens ilustrativas é muito pequena; em geral, são reproduções de pinturas, esculturas, caricaturas e fotos de pessoas, colocadas à margem direita ou esquerda do texto, o que impede, no caso das reproduções de obras de arte, a mínima leitura estilística ou apreciação estética. Dão a impressão que foram colocadas ali como uma necessidade editorial. Como a coleção traz a Literatura em capítulos separados, as páginas iniciais desses capítulos são abertas com um recorte de obra de arte no topo da página e com uma pequena legenda sobre a mesma. Cabe ressaltar o aspecto insuficiente e pouco produtivo de se colocar um "pedaço" de uma pintura como ilustração de um movimento artístico. Pouquíssimas obras ocupam um espaço proporcional ou nobre em relação ao texto verbal.

No mais, as ilustrações consistem em pequenos quadros, à esquerda ou à direita, com fotos dos autores-artistas do movimento e capas de livros ou fotogramas de cenas de adaptações cinematográficas de obras literárias. As dimensões dessas ilustrações são muito reduzidas, não chegando a $5 \%$ da área visual da página. Certamente isso tem a ver com os custos de se colocar imagens em formatos maiores, o que aumentaria as já numerosas 400 presentes. Sabemos que os LD não podem ser muito volumosos, já que os estudantes têm mais de um livro didático e os carregam o tempo todo.

Ainda assim, esse fato/o tamanho minúsculo das imagens construiu um sentido de que a ilustração não é importante e, por isso, a leitura de imagens ou textos multimodais acaba tornandose meramente a leitura do aspecto verbal mesmo do LD. Como gênero multimodal ou suporte de gêneros, o LDLP tem o desafio de apresentar e ensinar uma multiplicidade de gêneros e isso acarreta certa banalização da ilustração que se percebe quando não há praticamente nenhuma referência ao suporte, à dimensão, à técnica usada pelos artistas nas legendas das obras de arte, que trazem praticamente apenas o título da obra, nome do autor e ano. Em outras vezes, a legenda simplesmente faz a ponte entre essa ilustração visual e o tema da explicação teórica.

12 Uma das marcas da BNCC, no que tange ao ensino de Língua Portuguesa, é a profusão de gêneros discursivos que podem ser trabalhados. Não se trata de uma série fechada, isto é, além das dezenas gêneros multimodais apresentados, o documento traz a possibilidade de os professores incorporarem os novos gêneros (principalmente digitais) que forem sendo criados.

13 Falaremos sobre as tirinhas e os anúncios publicitários nas próximas seções. 
O sentido de se elaborar um LD ilustrado se perde em parte, talvez pela noção já apontada por Kress e Leeuwen (2006) segundo a qual nossa sociedade acredita que a leitura do verbal seja mais complexa que a do visual e que à medida que as crianças tornam-se adolescentes e adultos, vão dependendo menos do visual para compreender os conteúdos escolares, científicos ou artísticos. Assim é que nessa mesma coleção, do primeiro volume para o terceiro, as ilustrações tornam-se cada vez menores e há menos ilustrações artísticas, aquelas desenhadas para a obra. Essa semelhança de perfil de distribuição percentual e até mesmo o número de visuais (em torno de 230) se deve, acreditamos, ao perfil da coleção, a uma tomada de decisão editorial, e diz respeito a uma negociação entre autores, editoras, pré-requisitos do PNLD, entre outros motivos. No entanto, sem dúvida, tais essas escolhas implicam impactos importantes na metodologia e revelam deixam subentendidos pontos de vista pedagógicos específicos sobre a importância de letramento visual para os gêneros no LDLP.

Por exemplo, a quantidade de material visual do tipo ilustração ${ }^{14}$ já representa uma inflexão importante no ensino de Português de uns 40 anos para cá. À medida que fica mais barata a impressão/reprodução de materiais visuais, devido à evolução das técnicas de offset, de diagramação computadorizada, do acesso a um banco de dados de imagens livres de direitos autorais (final dos anos 1999) na internet, o texto verbal vem perdendo espaço para o visual. É como se houvesse uma demanda por um livro mais "atraente", se com isso se entende o livro com menos textos; ou que o texto ocupe na página espaço menor, disputado por toda sorte de quadros, recortes, títulos e subtítulos de atividades, etc. A afluência do material ilustrativo em termos quantitativos, sem dúvida alguma, diz respeito à pressão dos media audiovisuais, cada vez mais influentes em dizer o que atrai as crianças e adolescentes. Assim, os LDLP apresentam muitas fotos e menos ilustrações artísticas assinadas por um ilustrador, para contar com todo o acervo visual disponibilizado sem custo na rede mundial de computadores. Com isso, o LDLP perdeu texto e ganhou mais "brancos" entre colunas de palavras e mais imagens entre textos. Além do que, as imagens usadas para ilustrar certos tópicos ou exercícios, por serem colhidas na internet, nem sempre representam situações e personagens brasileiros.

Nada disso é prejudicial em si: sabemos que há teóricos defendendo que, quando a informação é transmitida por meio de mais de um recurso semiótico (palavra e imagem, por exemplo), a memorização, a compreensão se potencializam. Em artigo sobre o aprendizado multimodal, Dionísio e Vasconcelos (2013) mostram o quanto a ilustração pode ser uma aliada à aprendizagem, enriquecendo o verbal ou mesmo trazendo informações não disponibilizadas na parte verbal de um exercício, e também exemplos de usos irrelevantes ou mesmo contraproducente da utilização de dois recursos semióticos ao mesmo tempo (BUNZEN, 2003).

Acontece que, nos livros analisados, a maior parte da informação visual, as ilustrações, não tem qualquer importância para o que se deseja ensinar. Por exemplo, em um texto que serve de

14 Aqui chamamos ilustração qualquer elemento visual (fotos ou desenhos) que não seja objeto de análise detalhada, isto é, qualquer elemento visual que esteja em relação de complementação do verbal. A ilustração em nosso ponto de vista, teria um papel acessório se comparado com gêneros multimodais que são usados como textos-base de unidades didáticas, para serem objeto de análise enquanto gêneros discursivos e/ou para exercícios de interpretação ou análise linguístico-semiótica. 
base para um exercício de análise linguística, que tematizava dinossauros, vemos uma ilustração de um dinossauro. Tal modo é típico: ou a ilustração é meramente lúdica (para apreciação estética) ou redundante. Não se trata da ilustração como é feita nos livros de ficção ou de poesia para o público infantil. Ali o trabalho do artista ilustrador é feito para dialogar criticamente com o verbal, para neste introduzir sentidos, reforçar os sentidos da história contada, e assim por diante.

Pensamos que é uma espécie de desperdício de espaço da página a presença de informações visuais que pouco ou nada dialogam com as lições dadas. O trabalho de abordar a ilustração fica a critério do professor e possivelmente nem se abordam as imagens por sua redundância ou irrelevância para o tema da aula. Não estamos dizendo que LDs não devam trazer ilustrações, só questionamos se a onipresença da ilustração em cada página do livro não acaba levando a uma banalização visual, em que o olhar desliza sobre a figura sem sequer se questionar por que ela foi utilizada e nem reparar em seus elementos estéticos (quando feita exclusivamente para a coleção), no humor e na subjetividade (e em traços de humor e subjetividade).

Por conta de todos esses pontos levantados sobre a ilustração, acreditamos que os autores e editores precisam repensar a relação quantidade/qualidade da ilustração usada, reestabelecendo para esse visual a dignidade e importância que ele possui como ferramenta pedagógica, como formação de um leitor que possa fruir e aprender com as imagens, sem mimetizar o olhar distraído - padrão nas sociedades capitalistas ocidentalizadas, repletas de imagens que são consumidas sem serem "lidas" ou pensadas. O LDLP pode ajudar a recuperar a potência significante das imagens e isso começa pela valorização da ilustração, seu recurso visual mais usado. Como fazer isso? Aludindo, por exemplo, nos momentos em que a ilustração aparece, ao modo como a ilustração dialoga com o assunto trabalhado, chamando a atenção para elementos especificamente visuais: cor, tamanho, luz, forma, proporção, etc.

A tirinha, a charge e o cartum: abordagem unimodal de um gênero multimodal

Para nossa análise, devido a suas semelhanças formais/temático-enunciativas (como o uso da linguagem verbal e visual, do humor e da ironia, tipo de suporte, público-alvo etc.), decidimos considerar os três gêneros - tirinhas (HQs), cartum e charge - como o mesmo tipo de visual, mesmo sabendo que se trata de gêneros diferentes. Estamos, nesse momento, mais interessados em reconhecer os elementos não exclusivamente verbais do LDLP que mais são usados como recurso pedagógico.

Na coleção Se liga na língua, esses visuais apontados acima representam $25 \%$ (vol. 6) e $17 \%$ (vol. 9) de todos os visuais considerados para análise. É o segundo tipo de gênero mais usado nas lições de Língua Portuguesa. E, apesar de estar em segundo lugar em termos numéricos, do ponto de vista de sua utilização, é possível perceber que esses gêneros são muito mais importantes do que as ilustrações, que contabilizam de 70 a $85 \%$ de todos os visuais.

Isso se deve ao fato de que as tirinhas, as charges e os cartuns são objetos de reflexão explícita: exemplificam tópicos de análise linguística, são tratados em termos de gêneros, são até mesmo objeto de análise semiótica em alguns casos. 0 que não ocorre com as ilustrações dessa 
coleção que, na maioria das vezes, são realizadas na forma de desenhos que acompanham as lições ou textos mais como um complemento, ainda que sua expressividade criativa instigue o olhar da criança/adolescente, elemento extremamente importante para a qualidade de um livro que se queira ilustrado.

No caso do uso das tirinhas, charges e cartuns, tais gêneros praticamente "carregam" os tópicos gramaticais (análise linguística), seguidos de perto do anúncio publicitário. Em quase todas as unidades temos tirinhas ou charges como recurso explicativo de algum tópico de análise linguística. Tal fato é curioso, porque, junto com os textos do universo jornalístico e literário, correspondem a pelo menos $90 \%$ de todos os gêneros usados no LDLP. Os outros $10 \%$ são divididos em gêneros digitais, gêneros de outras formas de arte como dança, música, grafite, textos injuntivos como receitas, manuais, ou outros como infográficos, cartazes, roteiros, etc.

Como já dissemos, o modelo usado para ensino de Língua Portuguesa até a década de 1950 recorria a textos da tradição literária e, raramente, a textos filosóficos, religiosos ou ensaísticos como modelos de bem escrever ou de ensino de tópicos gramaticais puros. Na virada da década de 1950 para 1960, a influência do modelo comunicativo ${ }^{15}$ trouxe uma lufada de ar fresco aos materiais didáticos que começaram a utilizar anúncios publicitários, textos literários mais modernos e textos jornalísticos. O escopo da comunicação em língua escrita deixou de ser tão burocrático e passou a incorporar situações comunicativas outras que não as literárias, científicas ou jurídicas. Na década de 1970 tal modelo se ampliou até que, na década de 1980, já teríamos canções populares, tirinhas, entre outras formas de comunicação verbal e não verbal mais ligadas à modernidade. Evidentemente, tais marcos temporais são amplos e genéricos, não fazem parte de um levantamento exaustivo de todos os livros publicados ano a ano. $O$ fato, que pode ser conferido mais facilmente por qualquer professor mais experiente de Língua Portuguesa, é que agora esses gêneros multimodais (tirinhas, canções, anúncios publicitários) estão sedimentados nas aulas de Língua Portuguesa pela ocorrência cada vez maior nos LDs. A "última fronteira" tem sido a incorporação dos gêneros digitais e em rede, que amplia ainda mais a necessidade de uma abordagem multimodal dos gêneros.

Embora extremamente utilizada, é preciso se perguntar de que modo, nessas coleções, a tirinha é lida e usada em lições de Língua Portuguesa. Na coleção Se liga na língua, a tirinha e a charge são objetos de estudo sistemático em dois capítulos do volume 6 . Nesses capítulos, as características desses gêneros são abordadas primeiramente do ponto de vista de sua compreensão para depois servirem como subsídios em atividades de produção textual. Elementos não verbais são trabalhados, ainda que de modo um pouco elementar, pois se trata de um volume para o $6^{\circ}$ ano de escolaridade, com estudantes em torno de 10/11 anos. Apesar disso, especificamente nesses dois capítulos, a coleção vai além da abordagem do sentido dos balões de fala, uma característica importante da linguagem dos quadrinhos. Usando um método mais indutivo, com exemplos alavancando os conceitos e características gerais do gênero, os autores chamam a atenção para vários elementos visuais das tirinhas, para seus objetivos comunicativos, para a questão do desenho (do modo de representar os personagens) etc. O aspecto visual é trazido com relativa completude.

15 Nessa época, em especial na década de 1970, populariza-se nos LDLP o uso do esquema comunicativo de origem em Roman Jakobson, com as chamadas "funções da linguagem. (Cf. JAKOBSON, 2010, p. 150-207) 
Faltou, a nosso ver, elencar a importância e o sentido do espaço entre os quadrinhos - a sarjeta - e um trabalho melhor com a noção de caricatura, que ajudaria na composição do efeito de humor. 0 capítulo se encerra com atividades muito bem orientadas e detalhadas de produção de uma tirinha pelos estudantes.

No entanto, ao longo do volume 6 e em praticamente todo o volume 9 dessa coleção, quando as tirinhas aparecem para exemplificar tópicos de análise linguística, na parte teórica ou nos exercícios, o aspecto visual da tirinha e da charge quase nunca é mencionado, a não ser por referências muito vagas ao que "acontece" na tira. Talvez isso se deva ao fato de que os autores, por pressão do próprio espaço disponível para abordar o tópico, tenham priorizado os elementos verbais do gênero. A nosso ver, isso acaba por transformar um gênero multimodal em um gênero unimodal (no caso, verbal) ao longo dos quatro anos do Ensino Fundamental II e nos três do Ensino Médio. No exemplo abaixo, temos um típico modelo de uso da tirinha.

Figura 2 - Uso da tirinha na coleção Se liga na língua Oração e período

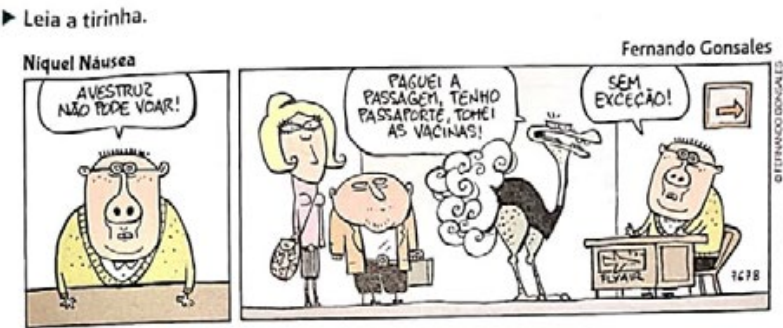

O que o leitor provavelmente imagina quando lê o primeiro quadrinho?

O humor se constrói pela quebra de expectativa. O que levou, de fato, o per-

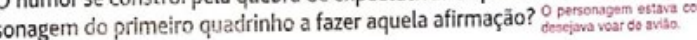
Essas três irases scio de um único tipo. Qual? O que explica essa predominância?

Quais säo as iornas ou locuçò es verbais presentes em cada fala?

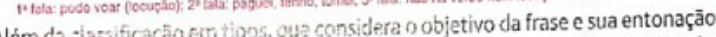

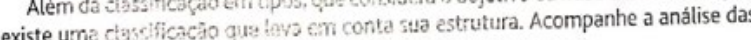
existe ume cts

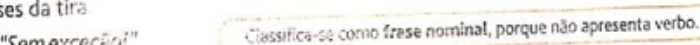

Classifica-se como oraçäo, porque apresenta um único

"Avestruz năo pode voar!" "Pagueia passagem, tenhopassaporte, tomeias vacinas!" $\underbrace{\begin{array}{c}\text { Classifica-se como periodo } \\ \text { composto, porque é formado }\end{array}}$

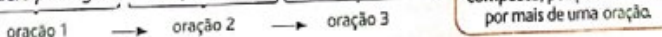

As oraçōes podem ser constituidas por uma ou duas unidades. O predicado é a

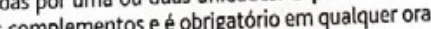
unidade que contemo verbo e seus complementos e é obrigatorio qual o verbo declara ção. $O$ sujeito é a unidade que contém algo e nem sempre está presente. Veja.

$$
\begin{aligned}
& \underbrace{\text { Avestruz }}_{\text {sujeito }} \underbrace{\text { năo pode voar!" }}_{\text {predicado }} \\
& \text { (eu) } \underbrace{\text { Paguei a passagem. }}_{\text {predicado }} \\
& \text { Chovia demais naquele instante. }
\end{aligned}
$$$$
\text { O sujeito existe, mas está oculto. }
$$

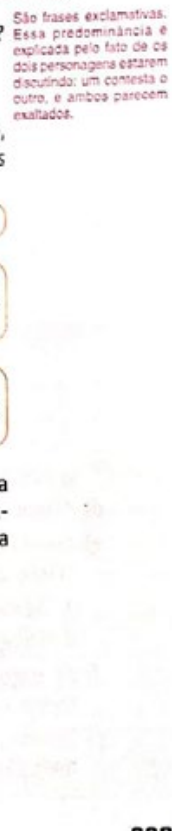

Fonte: ORMUNDO; SINISCALCHI, 2017, p. 239. 
No enunciado do exercício, segundo os autores, o humor se dá pela quebra de expectativa em relação ao interlocutor do quadrinho. Para que houvesse essa possibilidade de equívoco, o artista enquadrou o homem de frente, olhando para o leitor. Essa forma de composição visual é o que possibilita a confusão e, consequentemente, o humor. Bem como o aspecto caricatural das figuras representadas, típicos das tirinhas de Fernando Gonzales. O homem é representado de óculos, aparentemente mais velho, assumindo um lugar "professoral", de quem dá uma aula (as mãos na mesa sugerem que o personagem esteja dando palestra ou aula), leva o leitor a imaginar um contexto da frase que não se realiza no segundo quadrinho. Assim, não é apenas o que é dito, mas o quê e como é mostrado e não mostrado no primeiro quadrinho.

Nesse caso, os autores não exploraram tal construção da cena comunicativa na pergunta e na explicação. Observe-se a insistência no verbo "ler" - que não é exclusiva dessa coleção - na instrução do enunciado "Leia a tirinha" e na primeira questão "O que o leitor provavelmente imagina quando lê o primeiro quadrinho?". Como sabemos, ler pode ser uma produção de sentido a partir de textos visuais, sonoros, multimodais. No entanto, é comum que os exercícios insistam no conteúdo dos balões e menosprezem os elementos visuais.

Como iremos mostrar na coleção Português: linguagens, a leitura da tirinha vai se tornando praticamente um gênero em que a menção ao verbal predomina, a julgarmos pelas atividades propostas nos exercícios, ou nas reflexões teórico-metalinguísticas de análise linguística. $O$ universo da tirinha, enquanto gênero, é claramente muito dependente do verbal, porque, do ponto de vista do visual, do espaço que podiam ocupar num jornal no qual originalmente aparecem as primeiras tiras, o que interessa é a rapidez comunicativa. Pelas pressões do espaço em que ocupavam e ainda ocupam na página do jornal, o aspecto visual não pode ser tão elaborado em detalhes quanto em outras gêneros multimodais. Por exemplo, um livro ilustrado reserva à ilustração um lugar de destaque e, por isso, o artista pode usar elementos visuais mais detalhados e sutis. Ainda que 0 visual seja importante, na tirinha, o visual fica no primeiro plano.

Nas HQs mais modernas, publicadas independentemente do suporte jornalístico ${ }^{16}$, isso não acontece. Ali, o desenho e a estruturação ousada são muito mais importantes que as falas. A tirinha é como uma piada verbo-visual: tem que ser econômica em recursos, rápida, para obter o efeito de humor. Ela possui requinte visual de que outros gêneros multimodais, mesmo que o desenho de cada autor, o personagem, seja o que conecte fortemente ao leitor. Tudo o que foi apontado sobre a importância do verbal no universo da tirinha sugere o motivo que a levou a se tornar a "estrela" dos livros didáticos. Gera empatia com o estudante que, muitas vezes, já conhece os personagens de desenhos animados.

Entretanto, a onipresença da animação no mundo moderno não quer dizer que os estudantes não precisem de um espaço para reflexão sistemática sobre o aspecto visual das tirinhas. $O$ trabalho de autoria, de estilo pessoal, de uso da cor, forma, linha, exagero ou realismo da representação carregam sentidos importantes e precisam ser objeto de debate e aprendizagem, para que o gênero

16 Nesse caso, temos as histórias em quadrinhos propriamente ditas (não apenas tiras), muitas vezes chamadas de arte sequencial, temos os animes e um universo artístico complexo. 


\section{ARTIGOS}

não seja excessivamente "escolarizado", conforme apontam Dolz e Schnewly (2011) ${ }^{17}$, isto é,não transformarmos a leitura de tirinha numa atividade puramente escolar, despida do encanto que nos traz fora desse contexto. Não custa lembrar que há muitos exemplos de tirinhas, charges, cartuns em que o verbal não aparece. $O$ que nos leva a inferir que: se o verbal pode desaparecer na tirinha ou charge, mas o visual, não, então a linguagem visual é mais fundamental ao gênero do que a linguagem verbal.

Na coleção Português: linguagens, a tirinha mantém destaque como segundo visual mais usado depois da ilustração: $10 \%$ no volume 1 e $7 \%$ no volume 3 . Notamos que há uma diminuição numérica expressiva se compararmos com seu uso nos livros didáticos para o Ensino Fundamental II. $O$ que pode ser entendido da seguinte maneira: ainda que haja muita ilustração - em praticamente toda página temos pelo menos uma -, as ilustrações e mesmo outros visuais e gêneros aparecem em tamanho bastante reduzido, impedindo, por vezes, a simples identificação de elementos verbais ou visuais, e comprometendo a leitura pelo estudante. É como se o visual perdesse importância para a habilidade de leitura do verbal, que agora domina a mancha da página, que possui menos espaços brancos para descanso de leitura.

Nessa coleção, na maioria absoluta dos casos, a tirinha é usada para exemplificar tópicos de análise linguística. Os autores, durante a explicação de um tópico gramatical, como colocação pronominal, registro linguístico, ortografia, linguagem figurada ou literal, etc., fazem referência aos elementos verbais da tira praticamente todas às vezes em que aparecem tirinhas ou charges. No primeiro volume da coleção, destinado ao $1^{\circ}$ ano do Ensino Médio, há um capítulo que discorre sobre a diferença entre linguagem verbal e não verbal. Nesse capítulo, há uma referência ao fato de que a imagem compõe o sentido de textos multimodais (sem que se use tal nomenclatura). Aparecem alguns exemplos de textos multimodais (basicamente, anúncios publicitários e quadrinho), nos quais elementos visuais diversos são responsáveis pela construção do sentido do texto. Talvez aí seja o único momento em que, nas atividades, o estudante seja orientado a prestar atenção aos gestos dos personagens do quadrinho para construir hipóteses que orientarão a leitura e a resposta.

Depois, em todas as outras vezes que as tirinhas, charges e cartuns são utilizados, a referência ao visual praticamente desaparece. Em alguns casos, porém, os autores pedem que o estudante responda algo a partir da observação geral do que acontece na tira, sem entrar em detalhes sobre a forma como os personagens são representados, como o ambiente em que estão é representado, como pequenos elementos visuais compõem o sentido de maneira fundamental para a compreensão do humor da tira. Aliás, o humor é o efeito de sentido básico esperado em uma tirinha e a instrução mais colocada nas atividades de leitura, bem como seu "conteúdo temático". Na concepção de gênero bakhtiniana, "todo gênero tem um conteúdo temático determinado: seu objeto discursivo e finalidade discursiva, sua orientação de sentido específica para com ele e os outros participantes da interação" (RODRIGUES, 2005, p.167), ou seja, todo gênero possui sua intenção comunicativa.

Os exercícios dessa coleção frequentemente fazem referência ao "humor" da tira. Mas também é muito comum o uso da tirinha orientando o estudante a prestar atenção e "ler" apenas as palavras

17 Os autores nos lembram que, ao trabalhar as sequências didáticas dos gêneros, os professores devem tentar reproduzir as necessidades comunicativas a que tais gêneros respondem no contexto real de uso onde aparecem. Por isso, faz-se necessário um cuidado muito grande em construir na escola situações comunicativas em que os gêneros ensinados sejam fundamentais. 
do texto multimodal que é a tira. Os exercícios que usam tirinhas como texto-base para interpretação praticamente; começam com o enunciado "Leia a tirinha abaixo" e daí segue-se uma referência às falas dos personagens nos balões: o que esses dizem, como podem ser entendidas as expressões usadas, etc. Temos também exercícios em que os autores retiram palavras do balão e pedem ao estudante para completar de acordo com as instruções. Embora os autores elaborem exercícios ou usem a tirinha como base para exercícios de análise linguística, com ênfase na instrução de sentido que o termo ou tópico gramatical trazem à compreensão global do texto, em muitos casos, a abordagem mantém-se fiel ao paradigma tradicional de ensino da gramática, como podemos ver no exemplo abaixo.

Figura 3 - Uso da tirinha para o ensino de gramática

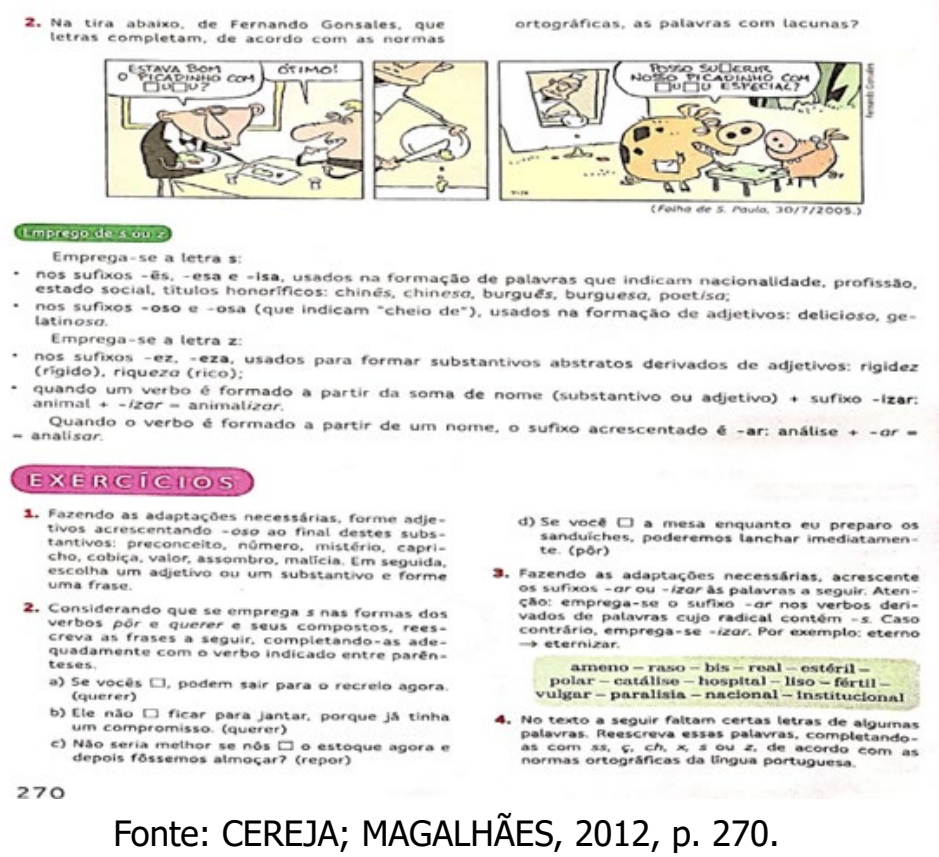

Observe-se como a tirinha é um mero pretexto para um exercício de ortografia. Não podemos dizer que isso seja compatível com uma abordagem do ensino de gramática enquanto análise linguística, isto é, em que o conhecimento das estruturas da língua, de seus componentes tem papel relevante para a construção de sentido do gênero Mendonça $(2005$, p. 196, 226) traça um quadro mais detalhado e explicita as diferenças entre um ensino gramatical tradicional, calcado na nomenclatura, na classificação metalinguística e a análise linguística, mais voltada ao funcional, ao epilinguístico, entre outros elementos metodológicos.

0 anúncio publicitário: consumir ou reconstruir sentidos e representacọ̃es?

Nas duas coleções observadas nesse estudo, percebemos que o uso de anúncios publicitários é bastante expressivo. Apesar de muito popular como objeto de conhecimento, esse gênero ainda é trabalhado de maneira bastante irregular nos LDLPs. As abordagens vão desde o uso para a pura 
exemplificação de tópicos de análise linguística, até um estudo mais aprofundado sobre os objetivos do anúncio, a relação texto verbal e visual, etc.

No volume 6 da coleção Se liga na língua, há 13 anúncios publicitários ${ }^{18}$. Inclusive existe um capítulo que trata do anúncio como gênero, com atividades de explicação teórica, exercícios de leitura e produção de anúncio. Ali, os autores têm um cuidado especial em tratar também de aspectos enunciativos, como público-alvo, produtor do anúncio etc. Em praticamente todos os enunciados, encontramos reflexões ou perguntas sobre a imagem ou montagem visual, o que ou quem é representado na imagem e que relação isso tem com a parte verbal ou com a construção do sentido do texto publicitário como um todo. Poucas são as ocorrências de uso do texto publicitário apenas para exemplificar um tópico teórico (geralmente gramatical) ou que não aborde o visual.

Em geral, as atividades (questionários que abrem um tópico teórico ou na seção de fixação ou exercícios) enfatizam o verbal, já que apenas em alguns casos há um equilíbrio entre a reflexão sobre o visual e o verbal. Em raras ocasiões, os autores abordaram exclusivamente a linguagem visual do cartaz. Ainda é comum a presença de questões muito genéricas do tipo "qual a relação entre a imagem e o texto/parte verbal do anúncio?", que não orientam o estudante para alguns aspectos importantes do anúncio. Os anúncios escolhidos como ponto de partida tratam de temas importantes como violência, poluição, entre outros problemas sociais; ainda assim, encontramos pouca reflexão crítica sobre o consumismo, sobre a influência, às vezes deletéria, da publicidade em reforçar estereótipos, hábitos alimentares ruins, exagerar qualidades ou disfarçar problemas com o consumo.

Em nenhuma das vezes em que esse gênero apareceu, foi possível encontrar referência ao "suporte" do gênero, isto é, se o anúncio está numa revista, jornal, outdoor ou outro suporte. E isso tem implicações importantes na composição do anúncio, no tamanho e registro linguístico do texto verbal e no uso das imagens, como tamanho, disposição, cor, etc. Entendemos que o suporte carrega sentidos importantes para a leitura.

No volume 9 dessa coleção, tal perfil de utilização se mantém: dos 9 anúncios usados, apenas dois não trazem nenhuma referência ao aspecto visual do texto. Em geral, predomina ainda a orientação ou atividade genérica que pede "a relação entre a imagem e o texto", sem explorar os elementos visuais em seus aspectos propriamente semióticos: cor, posição, dimensão, etc., ou técnicas de representação fotografia, caricatura, desenho, entre outras. Impera uma menção que toca de modo um tanto superficial: a questão do gênero textual. Como aconteceu no volume 6 , o fato de ser um texto multimodal, este não é explorado em toda a sua potencialidade de sentido. Por fim, um problema que aparece nos dois volumes, ainda que em menor frequência, é o tamanho de algumas reproduções de anúncios que, de tão diminutas, impossibilita aos estudantes a simples identificação das figuras ou imagens do anúncio. Embora a maioria dos anúncios da coleção possua um tamanho adequado para uma leitura mais minuciosa.

Na coleção Português: linguagens, nos volumes 1 e 3, utilizados no início e no fim do

18 Desconsideramos o uso de cartazes de filmes, que têm objetivo publicitário, mas são tratados no livro de modo diferente, sem referência ao seu caráter de divulgação publicitária nem de sua composição; quase sempre aparecem como ilustração. 
primeiro e o último ano do Ensino Médio, encontramos uma abordagem dos anúncios publicitários bastante parecida. Esse é o terceiro gênero multimodal mais utilizado, depois da ilustração e da HQ. Em ambos os volumes, há em torno de 20 anúncios publicitários como ponto de partida de exercício ou como base para explanação teórica. Destes, cerca de $50 \%$ não abordam de modo algum as imagens do texto, desprezando totalmente a mutlissemiose ou multimodalidade do gênero escolhido. Também como na outra coleção, boa parte dos anúncios é reproduzida em fotos tão pequenas que é impossível ler e, às vezes, identificar pelas imagens ou palavras o que é anunciado.

Por um lado, quando o anúncio publicitário aparece como texto-base para uma atividade de fixação da teoria gramatical, há um trabalho mais orgânico entre aspectos metalinguísticos e epilinguísticos. $\mathrm{E}$ um ponto bastante positivo nessa coleção é a abordagem frequente das questões enunciativas do gênero, como por exemplo, menções ou perguntas quanto à finalidade do texto, ao público-alvo, ao anunciante, etc. Essas questões denotam a incorporação da abordagem a partir do gênero discursivo, de teorias de cunho bakhtiniano que estão presentes nos documentos oficiais desde os PCNs $^{19}$ e agora completamente desenvolvidos na BNCC.

Poe outro lado, são muito raros os exercícios ou atividades em que o texto publicitário é usado como pretexto para nomenclatura gramatical, pura e simplesmente. Em geral, predomina a menção ao tópico de análise linguística associada ao sentido e à função que possui naquele texto específico. Falta, contudo, a referência ao suporte em que os anúncios aparecem. Raramente (em apenas dois casos nos livros analisados) isso foi colocado. Sabemos o quanto o suporte interfere na composição, na relação linguagem verbal e visual, no registro linguístico usado, na quantidade de informação verbal usada, etc. Desse modo, a própria opção dos autores/editores em utilizarem tantos anúncios publicitários com reproduções diminutas e sem muita referência aos veículos onde circulam comprometem fortemente a compreensão do texto. MARCUSCHI (2008), em obra já clássica sobre gêneros, faz importante reflexão sobre a o locus físico em que o gênero se manifesta e de que modo o suporte interfere decisivamente na sua estruturação. Também aponta a complexidade e o aspecto controverso da delimitação do suporte e de, às vezes, ser complicado separar suporte do próprio gênero. Nessas páginas o autor defende a posição que também assumimos de tratar o livro didático como suporte de gêneros. (Ver: MARCUSCHI, 2008, p. 173-186) O exercício abaixo mostra um tratamento bastante frequente na coleção no que tange ao tema e quantidade de exercícios sobre um anúncio publicitário.

19 PCN - Parâmetros Curriculares Nacionais. 
Figura 4 - Uso do anúncio publicitário na coleção Português:linguagens

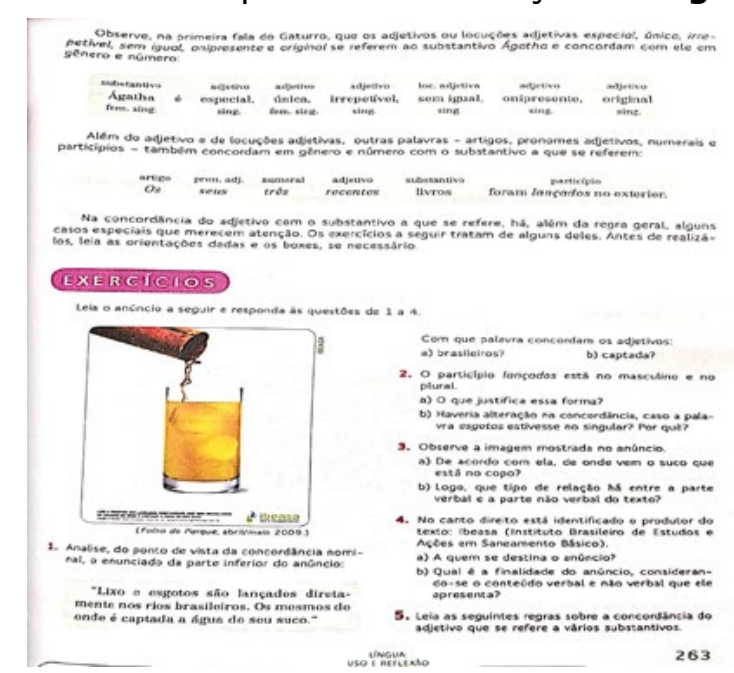

Fonte: CEREJA; MAGALHÃES, 2013, p. 263, v. 3.

O tamanho reduzido do anúncio no conjunto da página obriga os autores a reproduzir a parte verbal no enunciado dos exercícios. As questões 1 e 2 são de nomenclatura gramatical, sobre concordância nominal. Não trazem qualquer contribuição para a compreensão da função comunicativa do anúncio, que é alertar para a poluição dos rios, que nos oferecem água para viver. A questão 3 trata da imagem, mas o faz de modo muito vago, com a questão "que tipo de relação há entre a parte verbal e não verbal". Sabemos que a imagem serve para enfatizar, exagerar, impactar o leitor. $\mathrm{E}$, no caso em questão, a cor amarela do líquido no copo remete ao simultaneamente à palavra suco e à água suja, uma vez que sai de um cano enferrujado (assim pensamos, porque a imagem é um pouco confusa). Essa pergunta ("qual a relação entre o verbal e o não verbal?") aparece na coleção como uma fórmula usada em muitíssimos exemplos.

Dificilmente o estudante teria condições de abordar o visual dos anúncios, se a ele quase nunca é pedido para reparar no tamanho da imagem em relação à área ocupada pelo texto, à posição que imagem e texto ocupam, à simbologia das cores; à textura, ao contraste, etc. Os elementos fundamentais de uma sintaxe visual não são objeto explícito de reflexão. Também são muito ocasionais as referências às cores usadas nas figuras ou textos, dimensões e posições relativas das figuras, o tipo de técnica (naturalismo representativo, estilização, caricatura, técnicas mistas de composição, etc.). O que predomina são descrições muito vagas ou amplas das figuras representadas (quem ou o quê aparece na parte visual) e perguntas vagas como "qual a relação com o verbal", deixando ao estudante a tarefa da analisar a parte visual sozinho e relacioná-la ao verbal.

\section{Conclus̃̃o}

Ao longo de nossa análise procuramos identificar quais tipos de "visuais" e/ou gêneros multimodais incorporaram o visual e são mais usados nos livros didáticos de Língua Portuguesa. Os LDLPs analisados ainda não haviam incorporado as instruções da BNCC, por serem de elaboração 
anterior ao documento, mas já apresentavam algum tipo de abordagem dos elementos visuais de determinados gêneros, ainda que de forma não muito sistemática ou satisfatória. Também mostraram certo padrão comum: a ilustração ainda reina absoluta como o visual mais frequente, mesmo que pouco seja explorada nas atividades ou incorporada à "leitura", servindo como descanso visual da escrita, ou para deleite. Em todo caso, mesmo nos livros em que artistas compõem muitas ilustrações (como na coleção Se liga na língua) dando-lhes uma identidade visual, a sensação é a de que a ilustração é puramente acessória, não se integra ao desenvolvimento das habilidades de leitura e produção textual. Raramente são mencionadas e, se têm o papel de instigar a leitura, isso não aparece como parte das atividades.

A onipresente tirinha (bem como charges e cartuns) e o anúncio publicitários são os gêneros multimodais preferidos em ambas as coleções, talvez tal fato tenha ocorrido porque, ao contrário das ilustrações, são objetos de ensino-aprendizagem específicos e também usados para trazer exemplos de outros tópicos de análise linguística.

Acreditamos que contribuiu para esse uso maciço da tirinha e do anúncio o fato de serem muitas vezes divertidos e atuais, muito conhecidos dos estudantes e poderem ser colocados integralmente, sem recorte (já que são curtos). O lamentável é que, apesar de algumas unidades ou capítulos das coleções trazerem esses gêneros em detalhes, como gênero a ser lido e produzido, o aproveitamento ou menção ao visual se restringe quase sempre a esses capítulos; no restante dos livros, as tirinhas e anúncios aparecem praticamente como textos verbais, sendo muito esparso e superficial o trabalho com a semiose visual. Seguindo essa abordagem, a multimodalidade dos chamados gêneros virtuais ou das TICs ${ }^{20}$ - que aparecem pouco nas coleções - certamente não é trabalhada também de maneira apropriada.

A nosso ver, o grande desafio para os autores e editores de LDLP continua sendo encontrar um meio de trazer a multimodalidade de modo mais efetivo para o campo da leitura e produção textual e da análise linguístico-semiótica. Na BNCC encontramos a referência ao letramento multisemiótico em praticamente todos os campos de atuação, do literário ao jornalístico-publicitário, seja nas partes sobre leitura ou sobre produção textual. A escolha por separar a análise linguística e semiótica das partes de leitura e produção pode não ter sido ainda assimilada como os autores do documento desejaram e explicitaram: que a análise linguística e semiótica atravesse todos os campos, gêneros e atividades do currículo escolar. O fato de a BNCC separar graficamente, em campos específicos, a análise linguístico-semiótica da leitura e a produção não implica que essa análise deva ser desprezada ou considerada acessória. Se os LDLP não trouxerem a leitura multissemiótica para o centro das atividades, continuaremos a ver os mesmos gêneros multimodais terem seus elementos visuais tratados de modo subalternizado, acessório ou mesmo desprezado.

O desafio parece maior se pensarmos que as novas coleções certamente irão incorporar gêneros das TICs, que possuem multissemioses ainda mais complexas (por misturarem imagem em movimento, música e linguagem verbal) do que as dos gêneros encontradas nas coleções analisadas. O letramento visual é direito de todos e não tem nada de intuitivo ou especificamente artístico, por isso não é atribuição dos professores de Arte. Como ressalta Dondis (2003, p. 17), em

20 TIC - Tecnologia da Informação e Comunicação. 
obra seminal sobre letramento visual,

A abordagem visual do ensino carece de rigor e objetivos bem definidos. Em muitos casos, os alunos são bombardeados com recursos visuais - dispositivos, filmes slides, projeções audiovisuais -, mas trata-se de apresentações que reforçam sua experiência passiva de consumidores de televisão.

O letramento visual é urgente nos cursos de formação de professores de Letras para que o tratamento da multimodalidade aconteça efetivamente e com sistematicidade. Sabemos que o a semiose visual participa de modo central, e não auxiliar, na construção do sentido nesses e em outros gêneros multimodais. Caso contrário, estaremos antenados com as novas formas de comunicação social contemporâneas apenas na aparência e na teoria.

\section{Referências}

BRASIL. MINISTÉRIO DA EDUCAÇÃO. Base Nacional Comum Curricular. Brasília: MEC, 2017. Disponível em: http://basenacionalcomum.mec.gov.br/. Acesso em: 26 jan. 2021.

BUNZEN, Clécio. A fabricação da disciplina curricular Português. Revista Diálogo Educacional, Curitiba, v. 11, n. 34, p. 885-911, set./dez. 2011.

BUNZEN, Clécio; MENDONÇA, Márcia. Múltiplas linguagens para o ensino médio. São Paulo: Parábola, 2013.

CASSIANO, Célia Cristina de Figueiredo. O mercado do livro didático no Brasil: da criação do Programa Nacional do Livro Didático (PNLD) à entrada do capital internacional espanhol (19852007). 2007. 252 f. Tese (Doutorado em Educação) - Pontifícia Universidade Católica de São Paulo, São Paulo, 2007.

CEREJA, William Roberto; MAGALHÃES, Thereza Cochar. Português: linguagens. 9. ed. São Paulo: Saraiva, 2013. v. 1 e 3.

DIONISIO, Ângela Paiva; MACHADO, Anna Rachel; BEZERRA, Maria Auxiliadora (org.). Gêneros textuais e ensino. São Paulo: Parábola, 2010.

DIONISIO, Ângela Paiva; VASCONCELOS, Leila Janot de. Multimodalidade, gênero textual e leitura. In: BUNZEN, Clécio; MENDONÇA, Márcia (org.). Múltiplas linguagens para o ensino médio. São Paulo: Parábola, 2013. p. 19-42.

DOLZ, Joaquim; SCHNEWLY, Bernard. Gêneros orais e escritos na escola. 3. ed. Tradução Roxane Rojo e Glaís Sales Cordeiro. Campinas: Mercado das Letras, 2011.

DONDIS, Donis A. Sintaxe da linguagem visual. 2. ed. Tradução Luiz Jefferson Camargo. São Paulo: Martins Fontes, 2003.

JAKOBSON, R. Linguística e poética. In: JAKOBSON, R. Linguística e comunicação. 22. ed. Tradução Izidoro Bilkenstein e José Paulo Paes. São Paulo: Cultrix, 2010. p. 150-207.

KRESS, Gunther; VAN LEEUWEN, Theo. Reading imagem: the gramar of visual design. 2. ed. London: New York: Routledge, 2006. 
MANTOVANI, Katia Paulilo. O Programa Nacional do Livro Didático - PNLD: impactos na qualidade do ensino público. 2009. 126 f. Dissertação (Mestrado em Geografia Humana) - Faculdade de Filosofia, Letras e Ciências Humanas, Universidade de São Paulo, São Paulo, 2009.

MARCUSCHI, Luiz Antônio. Produção textual, análise de gêneros e compreensão. 3. ed. São Paulo: Parábola, 2008.

ORMUNDO, Wilton; SINISCALCHI, Cristiane. Se liga na língua: leitura, produção de texto e linguagem. São Paulo: Moderna, 2017. v. 6 e 9.

ROJO, Roxane; MOURA, Eduardo. Multiletramentos na escola. São Paulo: Parábola, 2012.

RODRIGUES, Rosângela Hammes. Os gêneros do discurso na perspectiva dialógica da linguagem: a abordagem de Bakhtin. In: MEURER, José Luiz; BONINI, Adair; MOTTA-ROTH, Désirée (org.). Gêneros: teorias, métodos, debates. São Paulo: Parábola, 2005. p. 184-207.

SOARES, Magda. Português na escola: história de uma disciplina curricular. In: BAGNO, Marcos (org.). Linguística da norma. São Paulo: Loyola, 2004. p. 155-177. 